\title{
Henri Godard, Louis Guilloux romancier de la condition humaine
}

\section{Emanuele Kanceff}

\section{Q OpenEdition \\ 1 Journals}

\section{Edizione digitale}

URL: http://journals.openedition.org/studifrancesi/33621

DOI: 10.4000/studifrancesi.33621

ISSN: 2421-5856

\section{Editore}

Rosenberg \& Sellier

\section{Edizione cartacea}

Data di pubblicazione: 1 décembre 2005

Paginazione: 675

ISSN: 0039-2944

\section{Notizia bibliografica digitale}

Emanuele Kanceff, «Henri Godard, Louis Guilloux romancier de la condition humaine», Studi Francesi [Online], 147 (XLX | III) | 2005, online dal 30 novembre 2015, consultato il 18 avril 2021. URL: http:// journals.openedition.org/studifrancesi/33621 ; DOI: https://doi.org/10.4000/studifrancesi.33621

Questo documento è stato generato automaticamente il 18 avril 2021.

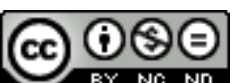

Studi Francesi è distribuita con Licenza Creative Commons Attribuzione - Non commerciale - Non opere derivate 4.0 Internazionale. 


\title{
Henri Godard, Louis Guilloux romancier de la condition humaine
}

\author{
Emanuele Kanceff
}

\section{NOTIZIA}

HENRI GODARD, Louis Guilloux romancier de la condition humaine, Paris, Gallimard NRF, 1999, pp. 421.

1 Secondo Godard, non è abbastanza chiaro a tutti che Louis Guilloux è stato uno dei romanzieri importanti del Novecento. Scopo del suo libro è di definire quali siano le ragioni della sua forte presenza e quale sia il posto che gli spetta tra i suoi contemporanei. La sua opera è in continuo dialogo con quelle di Malraux e di Céline. È un'opera impregnata della tragicità che deriva dalla contraddizione che dilacera l'uomo tra il desiderio che urge in lui e i limiti della realtà che vive. In Guilloux questo tragico si manifesta nell'intimo delle esperienze più comuni e più quotidiane, così come nelle lotte che è necessario condurre senza sosta contro quella parte d'intollerabile che ogni società contiene.

2 Questo libro studia prima di tutto Le sang noir, romanzo che viene considerato microcosmo e anamorfosi dell'opera. Accanto ad esso, prende posto l'analisi dei racconti d'infanzia, mentre una parte sostanziosa del libro è dedicata a "Les grandes chroniques" e un'ultima sezione definisce "Les bilans de vie". In effetti, l'A. vuole mostrare che le potenzialità artistiche del romanziere si ritrovano intatte negli altri suoi scritti, nelle grandi cronache come Le jeu de patience, che ricostruisce tutta la storia della prima metà del secolo, o in racconti d'infanzia dalla peculiarità inimitabile, come sono La Maison du peuple o Le pain des rêves, oppure, ancora, in quei due ultimi capolavori brevi che s'intitolano La confrontation e Coco perdu, bilanci che uomini in preda alla vecchiaia tentano di fare della loro vita e dell'esistenza. 